American Journal of Infectious Diseases 5 (3): 183-187, 2009

ISSN 1553-6203

(C) 2009 Science Publications

\title{
Studies on Emergence of Drug Resistance in HIV Associated Bacterial Urinary Tract Infections
}

\author{
${ }^{1}$ S.D. Deokar and ${ }^{2}$ M.G. Bodhankar \\ ${ }^{1}$ Department of Microbiology, Shri Shivaji Mahavidyalaya, Barshi (MS) 413411 India \\ ${ }^{2}$ Department of Microbiology, Bharti Vidyapith, Pune (MS) India
}

\begin{abstract}
Problem statement: This study was designed to document the prevalence of HIV associated urinary tract infections in Barshi Tahsil. Such studies had not been researched out before in this region. Approach: The study included samples from 123 HIV reactive and 40 HIV non-reactive patients. In both, mid stream samples were collected and processed to examine for bacterial opportunistic pathogens. The antibiogram of selected urinary isolates in HIV reactive as well as HIV non-reactive patients was studied by using disc diffusion technique and Kirby Bauer method. Study regarding molecular approach is in progress. Results: Urine samples from $75.46 \%$ of HIV reactive and $24.54 \%$ of HIV non reactive patients were culture positive. In all there were 74 urinary isolates from the HIV reactive cases. About $(36.48 \%)$ were E. coli, $(31.10 \%)$ were Pseudomonas aeruginosa and (24\%) were Klebsiella. These urinary isolates were found in different age groups of both male and female but more number of isolates was found in female as compared to male. In addition, E. coli and Klebsiella were predominant in female and Pseudomonas aeruginosa was found predominant in male. The antibiogram of selected urinary isolates in HIV reactive as well as HIV non-reactive patients indicates that urinary isolates in HIV reactive patients were more drug resistant than HIV non-reactive patients. Conclusion: The isolation of urinary opportunistic pathogens among the HIV reactive patients was found to be significantly higher than in HIV nonreactive patients. Also the antibiogram of urinary opportunistic pathogens in HIV reactive patients was significant finding indicating severity of the infection in this group.
\end{abstract}

Key words: UTI, HIV, Bacteriuria, Antibiogram, E. coli, Pseudomonas, Klebsiella

\section{INTRODUCTION}

The Acquired Immunodeficiency Syndrome (AIDS) Caused by Human Immunodeficiency Virus (HIV) is the most important public health problem of 20th century ${ }^{[3]}$. Though HIV infections made delayed into India, its spread has been very rapid and at present India hast the distinction of having the largest number of people living with Human Immunodeficiency Virus (HIV) in the world ${ }^{[2,19]}$. The Acquired Immunodeficiency Syndrome (AIDS) is in an advanced stage of the epidemic in some states of the country ${ }^{[2,19]}$. The infection is alarming due to the unique pathogenesis of the virus that decreases the CD 4 cells, signaling the emergence of the opportunistic infections, in the host ${ }^{[1,4,19]}$. Among the opportunistic infections, Urinary tract infections accounts for $60 \%$ of the AIDS defining illness ${ }^{[3]}$. Their relative importance differs in different parts of the world ${ }^{[3,4,14]}$. The present study was undertaken to note the prevalence of various bacterial isolates of urinary tract of HIV reactive patients among both female and male in different age groups and attempt was made to specifically examine antibiogram of selected urinary isolates in HIV reactive as well as HIV non reactive patients by Kirby Bauer method $^{[8,13,15]}$.

\section{MATERIALS AND METHODS}

Study design and patient selection: A study was conducted from May 2006 to September 2008 on HIV infected and HIV non infected patients in order to determine the prevalence of Urinary tract infections in HIV infected patients and the emergence of drug resistance in urinary pathogens. The entire tests were done after due patient consent and in accordance with institutional ethical guidelines. HIV infected patients were defined as those who had tested positive for HIV antibodies by two sequential ELISA/rapid tests as per the recommendations given by the $\mathrm{WHO}^{[17]}$. One

Corresponding Author: S.D. Deokar, Department of Microbiology, Shri Shivaji Mahavidyalaya, Barshi (MS) 413411 India Tel: 09822277165 
hundred and sixty three Symptomatic male and female patients to have UTI attending The Dr. J.M. Hospital and research center and Jawaharlal municipal hospital Barshi were enrolled in the study. All these patients were initially screened for anti HIV antibodies before being enrolled in the study.

Urine collection and examination: One hundred and twenty three HIV reactive study group 57 Male patients were asked to wash the hands with soap and also the glands. They were asked to pass urine after retracting the prepuce in the clean container. Sixty six Female patients were asked to pass the sterile swab from anterior to posterior side after parting the labia. In case virginal discharge was present an antiseptic solution savlon was used. The patient was then asked to pass the urine in clean container. Keeping the labia separated with hands. Midstream urine samples were collected in sterile containers by taking all precautions to avoid the contaminations. The urine specimens were immediately brought to the laboratory and cultured within $30 \mathrm{~min}$. In case of delay they were refrigerated at $4^{\circ} \mathrm{C}$ and cultured before $6 \mathrm{~h}$. Each sample was divided in to two equal parts; first part being utilized for culture while the second part was used for the detection of bacteriuria ${ }^{[1,6]}$.

Significant Bacteriuria was detected by microscopic examination wet mount and Grams staining. Five milliliter of urine sample was centrifuged for $5 \mathrm{~min}$ at $2000 \mathrm{RPM}$. The supernatant was discarded and deposit suspended in $1.0 \mathrm{ml}$ saline was examined microscopically. Calibrated loop (platinum loop with $4 \mathrm{~mm}$ diameter delivering $0.01 \mathrm{~mL}$ sample) used for bacterial analysis. Uncentrifuged urine was serially diluted with sterile saline and $0.1 \mathrm{ml}$ of diluted urine sample was poured and spread on sterile nutrient agar plate. One loopful of uncentrifuged urine sample was also streaked on Mac-Conkeys agar medium and Cysteine Lactose electrolyte deficient medium. Then the plates were examined after overnight incubation to quantify the organisms present by total viable count and any significant bacterial growth was further processed as per the standard procedure to identify the opportunistic pathogen ${ }^{[9,14,16]}$. Tetrazolium reduction test was also carried out for diagnosis of urinary tract infections ${ }^{[6,12]}$.

The antibiogram of selected urinary isolates in HIV reactive as well as HIV non-reactive patients was studied by disc diffusion technique on Mueller-Hinton agar medium by Kirby Bauer method ${ }^{[13]}$. The antibiotics used were Amikacin (10 mcg), Ampicillin (10 mcg), Nalidixicacid (30 mcg), Nitrofurantoin (30 $\mathrm{mcg})$, Norfloxacin (10 mcg), Cephotaxime (30 mcg), Gentamicin $(10 \mathrm{mcg})$ and Tetracycline $(30 \mathrm{mcg})^{[11]}$.
Statistical method: Statistical analysis was done using Chi square test to evaluate comparative urinary microbial profile in HIV reactive and non-reactive cases and any association between UTI, HIV infections and antibiotic resistance pattern. The results are noted in the text.

\section{RESULTS}

A total of 163 patient of UTI were examine for the presence of HIV infection from different age groups. Out of that 123 UTI patient found to be HIV reactive and 40 patient are non-reactive. Reactive group includes 57 male and 66 female cases. Non-reactive group includes twenty-three male and seventeen female cases (Table 1 and Fig. 1). Among the HIV positive reactive group 74 urinary opportunistic pathogens were isolated (Table 2 and Fig. 2) and 19 urinary opportunistic pathogens were isolated from HIV nonreactive group (Table 3 and 4, Fig. 2).

Table 1: Patients profile under study

\begin{tabular}{|c|c|c|c|c|c|c|}
\hline \multirow{2}{*}{$\begin{array}{l}\text { Age } \\
\text { group* }\end{array}$} & \multicolumn{2}{|c|}{$\begin{array}{l}\text { HIV reactive } \\
\text { group }\end{array}$} & \multicolumn{2}{|c|}{$\begin{array}{l}\text { HIV nonreactive } \\
\text { group }\end{array}$} & \multicolumn{2}{|c|}{$\begin{array}{l}\text { Total cases under } \\
\text { investigation }\end{array}$} \\
\hline & Female & Male & Female & Male & Female & Male \\
\hline B & 27 & 20 & 08 & 10 & 35 & 30 \\
\hline $\mathrm{C}$ & 33 & 28 & 05 & 08 & 38 & 36 \\
\hline D & 06 & 09 & 04 & 05 & 10 & 14 \\
\hline Total & 66 & 57 & 17 & 23 & 83 & 80 \\
\hline
\end{tabular}

B: (16-30 years); C: (31-45 years); D: (above 45 years)

Table 2: Comparative urinary microbial profile in HIV reactive and non reactive cases

\begin{tabular}{lllll}
\hline Sr. & $\begin{array}{l}\text { HIV reactive } \\
(\mathrm{N}=123)\end{array}$ & $\begin{array}{l}\text { HIV nonreactive } \\
(\mathrm{N}=40)\end{array}$ \\
No. Urinary isolates & culture positive & culture positive & p-value** \\
\hline 1 & E. coli. & 27 & 8 & 0.0790 \\
2 & Pseudo. aeruginosa & 23 & 7 & 0.0863 \\
3 & Kleb. pneumoniae & 24 & 4 & 0.0109 \\
& Total & 74 & 19 & 0.0162 \\
\hline
\end{tabular}

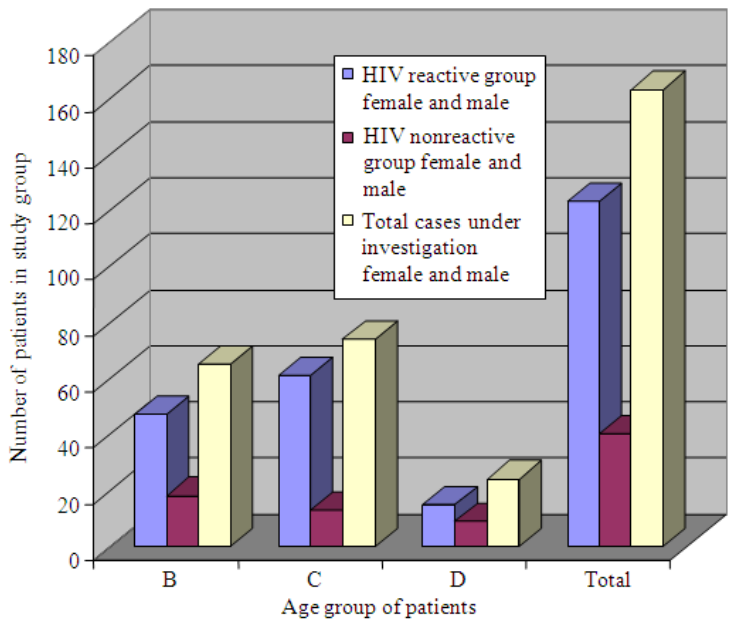

Fig. 1: Patient profile under study 
Am. J. Infect. Dis., 5 (3): 183-187, 2009

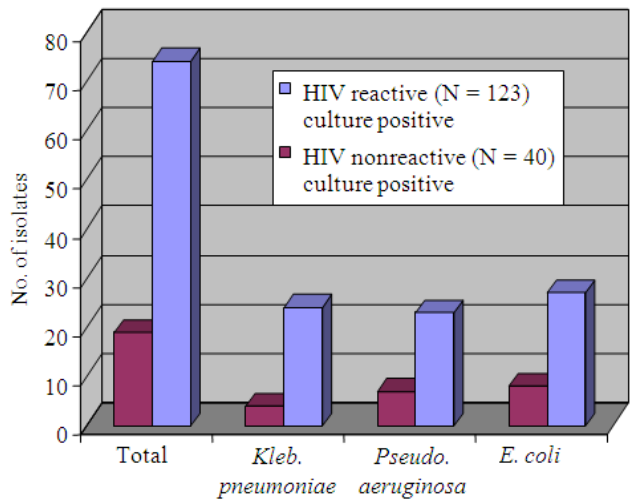

Fig. 2: Microbial profile of HIV reactive and non reactive cases

\begin{tabular}{|c|c|c|c|c|c|c|c|c|c|}
\hline \multirow{2}{*}{$\begin{array}{l}\text { Sr. } \\
\text { No. }\end{array}$} & \multicolumn{2}{|l|}{ E. coli } & \multicolumn{2}{|c|}{$\begin{array}{l}\text { Pseudo. } \\
\text { aeruginoa }\end{array}$} & \multicolumn{2}{|c|}{$\begin{array}{l}\text { Kleb. } \\
\text { pneumonia }\end{array}$} & \multicolumn{2}{|l|}{ Total } & \multirow[b]{2}{*}{ Total } \\
\hline & Female & Male & Female & Male & Female & Male & Female & Male & \\
\hline $\bar{B}$ & 7 & 3 & 2 & 6 & 7 & 3 & 16 & 12 & 28 \\
\hline $\mathrm{C}$ & 8 & 4 & 3 & 7 & 7 & 1 & 18 & 12 & 30 \\
\hline D & 3 & 2 & 1 & 4 & 4 & 2 & 8 & 8 & 16 \\
\hline Total 1 & & 09 & 06 & 17 & 18 & 06 & 42 & 32 & 74 \\
\hline
\end{tabular}

Table 4: Microbial profile of HIV nonreactive group

\begin{tabular}{|c|c|c|c|c|c|c|c|c|c|}
\hline \multirow{2}{*}{$\begin{array}{l}\text { Sr. } \\
\text { No. }\end{array}$} & \multicolumn{2}{|l|}{ E. coli } & \multicolumn{2}{|c|}{$\begin{array}{l}\text { Pseudo. } \\
\text { aeruginoa }\end{array}$} & \multicolumn{4}{|c|}{$\begin{array}{l}\text { Kleb. } \\
\text { pneumonia Total }\end{array}$} & \multirow[b]{2}{*}{ Total } \\
\hline & Female & Male & Female & Male & Female & Male & Female & Male & \\
\hline $\bar{B}$ & 2 & - & - & 3 & 1 & - & 03 & 03 & 06 \\
\hline $\mathrm{C}$ & 2 & 1 & 1 & 1 & 2 & - & 05 & 02 & 07 \\
\hline D & 2 & 1 & 1 & 1 & 1 & - & 04 & 02 & 06 \\
\hline \multicolumn{2}{|c|}{ Total 6} & 2 & 2 & 5 & 4 & - & 12 & 07 & 19 \\
\hline
\end{tabular}

The predominant isolates were E. coli $(36.48 \%)$, Pseudomonas $(31.08 \%)$ and Klebsiella $(32.43 \%)^{[15]}$. Among the 27 isolates of E. coli 18 were from female and 9 from male. Twenty three Pseudomonas isolates were detected in which 6 from female and 17 from male (Table 2). Similarly 24 Klebsiella isolates were found in 18 female and 6 male cases (Table 3). The distribution of 19 isolates in 40 HIV non-reactive cases includes 8 E. coli, 7 Pseudomonas and 4 Klebsiella.

It can be seen from the results that more number of urinary isolates were found in female than male. E. coli and Klebsiella were predominant in female and Pseudomonas was predominant in male (Table 3 and Fig. 2).

The isolation of urinary opportunistic pathogen among the HIV reactive patients was found to be significantly higher than in HIV nonreactive patients, 60.11 and $47.05 \%$ respectively. Also the antibiogram of identified isolates in HIV reactive patient is significant finding indicating severity of the infection in this group (Table 4 and Fig. 3$)^{[4,7,8]}$.

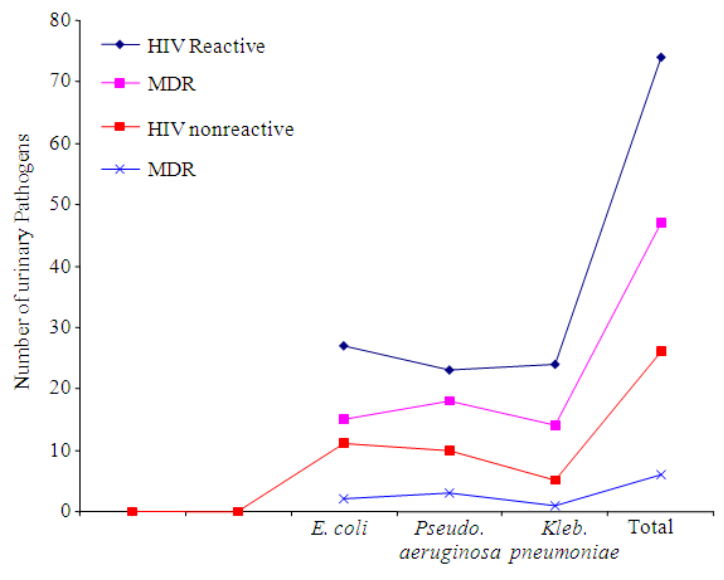

Fig. 3: Comparison of MDR in urinary pathogens

\begin{tabular}{|c|c|c|c|c|c|c|}
\hline $\begin{array}{l}\text { Sr. } \\
\text { No. }\end{array}$ & Urinary isolate & $\begin{array}{l}\text { HIV } \\
\text { Reactive } \\
(\mathrm{n}=123) \\
\text { Culture } \\
\text { positive }\end{array}$ & MDR & $\begin{array}{l}\text { HIV } \\
\text { Nonreactive } \\
(\mathrm{n}=40) \\
\text { Culture } \\
\text { positive }\end{array}$ & MDR & p-value $* * *$ \\
\hline 1 & E. coli & 27 & 15 & 11 & 2 & 0.013 \\
\hline 2 & Pseudo. aeruginosa & 23 & 18 & 10 & 3 & 0.004 \\
\hline 3 & Kleb. pneumoniae & 24 & 14 & 05 & 1 & 0.019 \\
\hline 4 & Total & 74 & 47 & 26 & 6 & 0.002 \\
\hline
\end{tabular}

\section{DISCUSSION}

The importance of Urinary tract infections in HIV reactive patients is well documented. The true incidence of these infections is difficult to Asses and varies with the population surveyed. In the present study 163 cases formed study group, out of which $123 \mathrm{HIV}$ reactive and 40 HIV non-reactive patients. Out of 123 HIV reactive patients the etiologic agent could be identified in 74 patients. Among the opportunistic infections associated with HIV reactive cases like UTI of bacterial origin occur at a rate many times higher in the HIV reactive group than in generality population. In the present study, the bacterial isolates from the HIV reactive group were much higher and varied etiology than those of HIV non-reactive group. Also the antibiogram of identified isolates in HIV reactive patient is significant finding indicating severity of the infection in this group. Multiple drug resistance among urinary isolates is also significantly variable ${ }^{[10,12,13]}$ (Table 5 and Fig. 3). Which may be due to repeated exposer to various drugs in HIV reactive cases (Table 5 and Fig. 3-6) Multiple drug resistance study of different isolates were shows that Klebsiella pneumoniae is more resistance to number of antibiotics as compare to E. coli and Pseudomonas aeruginosa (Fig. 4-6.) Detail molecular study of drug resistance is essential. 


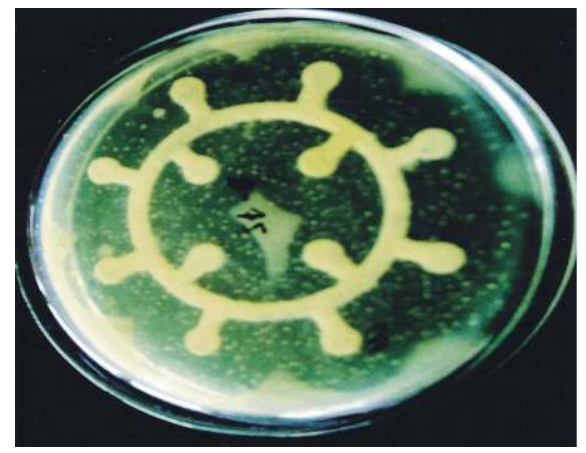

Fig. 4: Multiple drug resistance in Pseudomonas aeruginosa

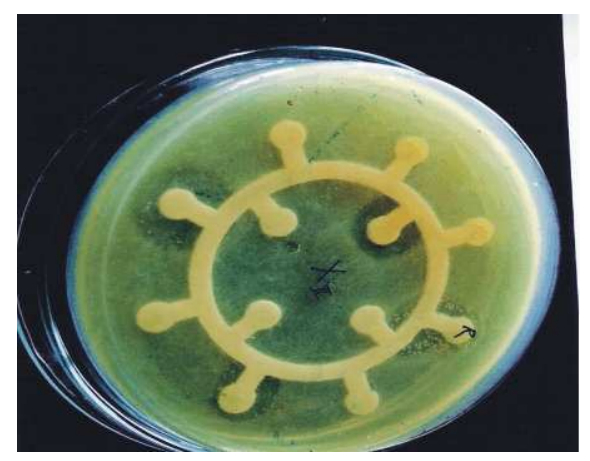

Fig. 5: Multiple drug resistance in Klebsiella pneumoniae

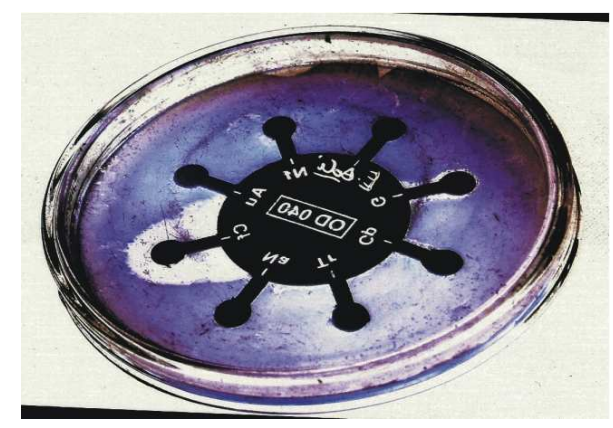

Fig. 6: Multiple drug resistance in E. coli

\section{CONCLUSION}

The isolation of urinary opportunistic pathogens among the HIV reactive patients was found to be significantly higher than in HIV nonreactive patients. Also the antibiogram of urinary opportunistic pathogens in HIV reactive patients is significant finding indicating severity of the infection in this group. In Previous study reported that the Pseudomonas aeruginosa shows resistance to number of antibiotics as compare to $E$. coli and Klebsiella pneumoniae but our findings are different i.e., Klebsiella pneumoniae is more resistance to number of antibiotics as compare to $E$. coli and Pseudomonas aeruginosa (Fig. 4-6).

\section{REFERENCES}

1. Joshi, P.L. and S.N. Mishra, Opportunistic Infections in HIV/AIDS Patients : An over view, Chapter 1. In: Manual on Laboratory Diagnosis of Common Opportunistic Infections Associated with HIV/AIDS. Baweja, U.K. and J. Sokhey (Eds.). Govt. of India, National Institute of Communicable Diseases, New Delhi, pp: 1-4. http://books.google.com.pk/books?id=n96-

GwAACAAJ\&dq=Manual+on+laboratory+diagnos is+of+common+opportunistic+infections+associate $\mathrm{d}+$ with+HIV/AIDS

2. Jindal Neeraj and Arora Usha, 2007. Trend of HIV infection in police personnel attending VCTC of a tertiary care hospital. Indian J. Commun. Med., 32: 201-202.

http://www.popline.org/docs/1772/321646.html

3. De Pinho, A.M., G.S. Lopes, C.F. Ramos-Filho, O.R. Da Santos, M.P. De Olivei, C.A. Gouvea and M. Scheehter, 1994. Urinary tract infection in Men with AIDS. Genitourinary Med., 70: 3-34. http://sti.bmj.com/cgi/reprint/70/1/30

4. Hannan, P.C.T., 1998. Comparative susceptibilities of various AIDS associated and human urinogenital tract Mycoplasma and strains of Mycoplasma pneumoniae to ten classes of antimicrobial 1 agents in vitro. Ind J. Med. Micro., 4: 1155-1122. (www.ijmm.org)

5. Mandal, P., A. Kapil, A. Goswami, B. Das and S.N. Dwevedi, 2001. Uropathogenic Escherichia coli causing urinary tract infections. Indian J. Med. Res., 207-211. http://www.ncbi.nlm.nih.gov/pubmed/3536737

6. Kunin, C.M., 1979. Detection, Prevention and Management of Urinary Tract Infections. 4th Edn., Henry Kempton Publishers, London, ISBN: 0812106806, pp: 381.

7. Hussain, R.A., B.J. Wadher, H.F. Daginwala, A.A. Pathak, A. Khan, B.S. Nagoba and S.R. Deshmukh, 1994. Antibiotic resistance pattern of organism causing urinary tract infections in Humans.Indihttp://www.google.com/searchmedical +gazette+vol+XXVIII,NO+7 pp 231-236.

8. Rashmi, K., M. Bibhabati and M. Anandita. 1992. Antibiotic susceptibility pattern of bacteria isolated from urinary tract infections with special reference to Norfloxacin. Indian J. Med. Micrbiol., 10: 91-93. (www.ijmm.org) 
9. Nath, G., M. Choudhary, J. Prakash, L.K. Pandey and T.B. Singh, 1996. Urinary tract infections during pregnancy and fetal outcome. Indian J. Med. Microbiol., 14: 158-160. http://medind.nic.in/imvw/imvw12781.html

10. Kaur, P., M. Jaysheela, A. Chakrabarty and S.N. Saxena, 1991. Chracteristics of E. coli isolates from cases of significant Bacteriuria. Indian J. Med. Microbiol., 9: 107-113. (www.ijmm.org)

11. Bhau, R., D. Gowal, A.P. Chaturvedi, M. Jaysheela and P. Agarwal, 1989. Prevalence of Escherichia coli serotypes in urinary tract infections. Indian J. Med. Microbiol., 7:21-25. (www.ijmm.org)

12. Agarwal, S.K., R. Das, M.M. Goel and M. Kumar, 1986. Tetrazolium reduction test in diagnosis of urinary tract infections. Indian J. Pathol. Microbiol., 29: 61-65.

http://www.ncbi.nlm.nih.gov/pubmed/3536737

13. Bauer, A.N. and W.M.M. Kirby, 1966. Sherris single disc method. Am. J. Clin. Pathol., 45: 493. http://ajcp.ascpjournals.org/site/subscriptions/trial. xhtml

14. Bhalla, P. and P. Aggarwal, 1989. Urinary Escherichia coli-prevalent serotypes antimicrobial susceptibility and virulence factors. Indian J. Med. Microbiol., 7: 88-90.
15. Desai, B., B. Mahajan and B.R. Panhotra, 1989. Transferable resistance to disinfectants in Klebsiella aerogenes: Correlation to gentamysin resistance. Indian J. Med. Microbiol., 7: 170-173.

16. Goyal, S.C., P. Singh, S. Khurana and S. Ram, 1994. Bacteraemia in urological surgical procedures. Indian J. Pathol. Microbiol. 37: 415-420. http://www.ncbi.nlm.nih.gov/pubmed/7868175

17. WHO., 2006. WHO case definition of HIV surveillance and revised clinical staging and immunological classification of HIV related disease in adult aged 15 years or older SEARO publication on HIV/AIDS. http://www.searo.who.int

18. Falags, M.E. and M. Polemis et al., 2008. Antimicrobial resistance of $E$. coli urinary isolates from primary care patients in Greece. Med. Sic. Monit., 14: CR75-CR79. http://www.ncbi.nlm.nih.gov/pubmed/18227764

19. National AIDS Control Organization (India), 2005. HIV/AIDS epidemiological surveillance and estimation report for the year 2005. NACO. http://www.aidsportal.org/repos/fnlapil06rprt.pdf 